\title{
Pyrolytic carbons derived from water soluble polymers
}

\author{
M. Molenda $\cdot$ A. Chojnacka $\cdot$ P. Natkański $\cdot$ \\ E. Podstawka-Proniewicz $\cdot$ P. Kuśtrowski • \\ R. Dziembaj
}

Received: 15 October 2012/ Accepted: 19 April 2013/Published online: 16 May 2013

(c) The Author(s) 2013. This article is published with open access at Springerlink.com

\begin{abstract}
Conductive pyrolytic carbon materials were obtained in wet impregnation process followed by controlled pyrolysis. Poly- $N$-vinylformamide (PNVF) as well as mixture of PNVF and pyromellitic acid (PMA) were applied as carbon precursors. Composition of carbon precursors was optimized in terms to obtain best electrical properties of pyrolytic carbons. Mixture of PNVF and PMA as well as pure PNVF were deposited on the model alumina $\left(\alpha-\mathrm{Al}_{2} \mathrm{O}_{3}\right)$ support to form conductive carbon layers (CCL). The optimal composition of the polymer precursors was determined by Raman spectra and electrical conductivity measurements. The carbonization conditions were optimized using complementary thermal analysis methods (EGA(FTIR)-TG/ DTG/STDA). It was found that the addition of PMA to polymer precursor PNVF decreases temperature of formation of condensed graphene structures, domains of electrical conductivity, thus, the formation temperature of pyrolytic carbons with desired electrical properties may be decreased.
\end{abstract}

Keywords Pyrolysis - Carbon coating - Conductive carbon layers (CCL) - EGA(FTIR)-TG · Raman spectra . Electrical conductivity

\section{Introduction}

One of the current directions in modification of electrode materials for lithium ion batteries is formation of composites by mixing the active materials with carbon additives

M. Molenda $(\bowtie) \cdot$ A. Chojnacka $\cdot$ P. Natkański

E. Podstawka-Proniewicz · P. Kuśtrowski · R. Dziembaj

Faculty of Chemistry, Jagiellonian University, Ingardena 3 Str., 30-060 Kraków, Poland

e-mail: molendam@chemia.uj.edu.pl
[1]. Such a composition is intended to improve a performance of the electrodes, but it is not sufficient. Aggregation of the fine carbon particles increases heterogeneity of the electrodes and decreases cell reversible capacity because of limitation in charge transport. In consequence, the active material is not fully exploited $[2,3]$. In order to obtain materials with improved performance, the active phase is coated by well-fitting, conductive carbon layer (CCL). CCL may be prepared from carboxylic acid [4], polyalcohols [5], resins [6] and sugars [7], however, increasingly important in production of carbon layers gains the hydrophilic polymers. The literature also indicates that the improvement of carbon coating structure is made by applying of pyromellitic acid as carbon precursor [8]. The method of formation of CCL was proposed in our recent articles [9, 10]. The present studies are focused on composition optimization of the polymer carbon precursor and process conditions resulting in formation of pyrolytic carbons with improved electrochemical properties. As carbon source, poly- $N$-vinylformamide (PNVF) as well as mixture of PNVF and pyromellitic acid (PMA) were applied. Mixture of PNVF and PMA (called MPNVF) and pure PNVF were deposited on the model alumina support $\left(\alpha-\mathrm{Al}_{2} \mathrm{O}_{3}\right)$ by wet-impregnation method, then a subsequent pyrolysis process was performed [11]. The carbonization conditions were optimized by complementary thermal analysis methods (EGA(FTIR)-TG/DTG/STDA). The resulting carbons and carbon coatings were characterized by Raman spectroscopy and electrical conductivity measurements.

\section{Experimental}

The PNVF was obtained by free-radical polymerization of $N$-vinylformamide (NVF) in aqueous solution. Freshly 
distilled monomer was dissolved in de-ionized water (preflushed with Ar for $30 \mathrm{~min}$ ) at room temperature under constant flow of argon. The initiator, 2,2'-azobis(isobutylamidine hydrochloride) (AIBA, Aldrich), was added and the reaction mixture (I:N $=0.05$ ) was heated up to $333 \mathrm{~K}$ for $2 \mathrm{~h}$. The obtained product was dried in an air dryer at $363 \mathrm{~K}$ for $24 \mathrm{~h}$. Prepared PNVF was separated into two series. The first series was a pure PNVF while the other series was MPNVF in the range of 2.5-15 mass\% of PMA. Both the series were pyrolysed under constant flow of $99.999 \%$ argon $\left(50 \mathrm{~mL} \mathrm{~min}^{-1}\right)$ within the temperature range of 823 and $873 \mathrm{~K}$ for 6 and $24 \mathrm{~h}$. The composition of carbon precursors and the conditions of pyrolysis process are presented in Table 1.

The content of PMA in the resulting carbon materials was optimized in terms of Raman spectroscopy and electrical conductivity measurements. MPNVF as well as pure PNVF were deposited on the alumina grains $\left(\alpha-\mathrm{Al}_{2} \mathrm{O}_{3}\right)$ suspended in water (wet impregnation process). Resulting carbon-alumina composites were pyrolysed under flow $\left(50 \mathrm{~mL} \mathrm{~min}^{-1}\right)$ of argon $(99.999 \%)$ at $873 \mathrm{~K}$ for $6 \mathrm{~h}$. Carbonation process was studied by thermal analysis methods (EGA(FTIR)-TG/DTG/STDA). The amount of carbon in the obtained $\mathrm{CCL} / \alpha-\mathrm{Al}_{2} \mathrm{O}_{3}$ composites was determined by temperature programmed oxidation (TPO) [9].

Measurement of the Raman spectra for the samples was performed at room temperature using a triple grating spectrometer (Jobin-Yvon, T 64000) with a CCD detector (Jobin-Yvon, Model CCD3000) cooled by liquid nitrogen. Raman spectroscopy measurements were performed on thin pellets containing $10 \mathrm{mg}$ of the sample and $200 \mathrm{mg}$ of $\mathrm{KBr}$. The spectral resolution of $2 \mathrm{~cm}^{-1}$ was set. An excitation wavelength at $514.5 \mathrm{~nm}$ was provided by an Ar-ion laser (Spectra-Physics Model 2025) with a power about $20 \mathrm{~mW}\left(32 \mathrm{~W} \mathrm{~cm}^{-2}\right)$. Raman scattered light was collected with $135^{\circ}$ geometry and 5,000 scans were accumulated to ensure acceptable signal-to-noise ratio.

Electrical conductivity of the materials was measured using the $a c$ 4-probe method within temperature range of 243-323 K. The obtained carbons and composite powders were elastic; therefore preparation of the pellets was impossible. The powder samples were placed into a glass tube and pressed by a screw-press between parallel gold disc electrodes $(\varnothing=5 \mathrm{~mm})$ till the measured resistance remained constant.

The TG-FTIR measurements were performed using TA Instruments SDT Q600 thermo-analyzer coupled with

Table 1 Composition of carbon precursors, conditions of pyrolysis process and electrical properties of resulting pyrolytic carbons

\begin{tabular}{|c|c|c|c|c|c|}
\hline Sample & $\begin{array}{l}\text { PMA content/ } \\
\%\end{array}$ & $\begin{array}{l}\text { Temperature of pyrolysis/ } \\
\mathrm{K}\end{array}$ & $\begin{array}{l}\text { Pyrolysis time/ } \\
\mathrm{h}\end{array}$ & $\begin{array}{l}\text { Electrical conductivity @ } 298 \mathrm{~K} / \mathrm{S} \\
\mathrm{cm}^{-1}\end{array}$ & $\begin{array}{l}\text { Activation energy/ } \\
\text { eV }\end{array}$ \\
\hline PNVF-1 & 0 & 823 & 6 & -3.8 & 0.18 \\
\hline PNVF-2 & & & 24 & -2.4 & 0.13 \\
\hline PNVF-3 & & 873 & 6 & -3.1 & 0.16 \\
\hline PNVF-4 & & & 24 & -1.4 & 0.08 \\
\hline MPNVF-1 & 2.5 & 823 & 6 & -3.07 & 0.16 \\
\hline MPNVF-2 & & & 24 & -1.87 & 0.13 \\
\hline MPNVF-3 & & 873 & 6 & -1.61 & 0.14 \\
\hline MPNVF-4 & & & 24 & -1.55 & 0.12 \\
\hline MPNVF-5 & 5 & 823 & 6 & -2.70 & 0.14 \\
\hline MPNVF-6 & & & 24 & -1.45 & 0.12 \\
\hline MPNVF-7 & & 873 & 6 & -0.98 & 0.11 \\
\hline MPNVF-8 & & & 24 & -0.57 & 0.07 \\
\hline MPNVF-9 & 7.5 & 823 & 6 & -3.51 & 0.17 \\
\hline MPNVF-10 & & & 24 & -2.29 & 0.14 \\
\hline MPNVF-11 & & 873 & 6 & -1.89 & 0.13 \\
\hline MPNVF-12 & & & 24 & -1.10 & 0.11 \\
\hline MPNVF-13 & 15 & 823 & 6 & -3.42 & 0.14 \\
\hline MPNVF-14 & & & 24 & -2.44 & 0.14 \\
\hline MPNVF-15 & & 873 & 6 & -1.64 & 0.12 \\
\hline MPNVF-16 & & & 24 & -0.51 & 0.10 \\
\hline $\begin{array}{l}\mathrm{MPNVF} / \alpha- \\
\mathrm{Al}_{2} \mathrm{O}_{3}\end{array}$ & 5 & 873 & 6 & -3.09 & 0.12 \\
\hline $\mathrm{PNVF} / \alpha-\mathrm{Al}_{2} \mathrm{O}_{3}$ & 0 & & & -3.72 & 0.13 \\
\hline
\end{tabular}




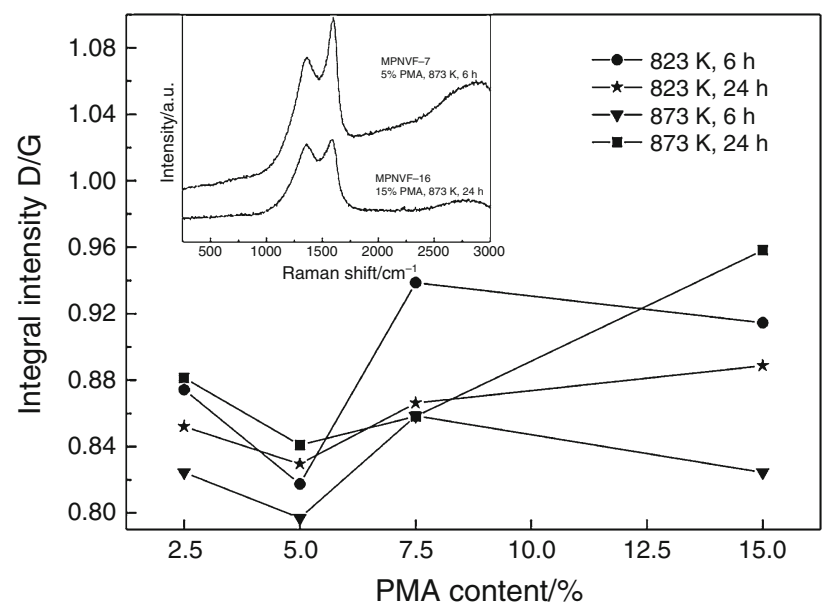

Fig. 1 Integral intensity ratio of D/G Raman bands for pyrolytic carbons derived from MPNVF with various PMA content at different pyrolysis conditions (temperature, time) and sample Raman spectra for samples: MPNVF-7, MPNVF-16

Nicolet 6700 FT-IR (Thermo Scientific) spectrometer equipped with FTIR-TG (Thermo Scientific) accessory. The experiments were carried out in temperature in nitrogen flow $\left(20 \mathrm{~mL} \mathrm{~min}{ }^{-1}\right)$ in a temperature range of $303-1,273 \mathrm{~K}$ at a heating rate of $10 \mathrm{~K} \mathrm{~min}^{-1}$. The sample mass was about $20 \mathrm{mg}$ in each run. The FT-IR spectral maps of gaseous products formed during experiments were recorded with resolution of $4 \mathrm{~cm}^{-1}$ collecting eight scans for each spectrum. TPO was performed in Mettler-Toledo $851^{\mathrm{e}}$ thermo-analyzer. Samples were prepared in $150 \mu \mathrm{L}$ corundum crucibles under flow of air $\left(80 \mathrm{~mL} \mathrm{~min}^{-1}\right)$, within the temperature range of 303-1,073 K with heating rate of $10 \mathrm{~K} \mathrm{~min}^{-1}$.

\section{Results and discussion}

Graphitization degree of obtained carbons was evaluated using Raman spectroscopy from integral intensity ratio of

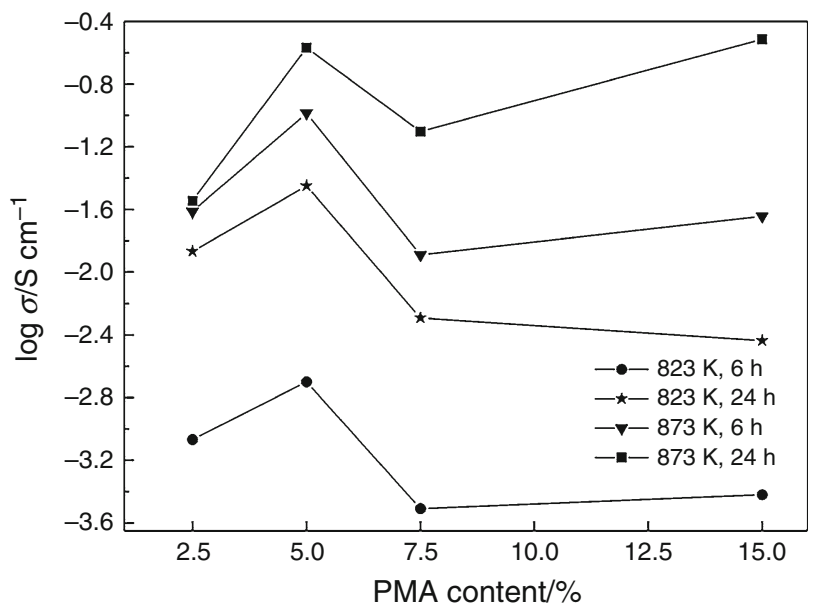

Fig. 2 Electrical conductivity of the pyrolytic carbons derived from MPNVF with various PMA content at different pyrolysis conditions (temperature, time)

$\mathrm{D}$ band (disordered $\mathrm{sp}^{3}$, observed at around $1,350 \mathrm{~cm}^{-1}$ ) to $\mathrm{G}$ band (graphene $\mathrm{sp}^{2}$, observed at around $1,600 \mathrm{~cm}^{-1}$ ). The Raman spectra (Fig. 1) showed that the increase of the pyrolysis temperature as well as increase of pyrolysis time caused decrease in the D/G ratio confirming better graphitization of the carbonized samples. Comparison of $\mathrm{D} / \mathrm{G}$ ratio of derived carbons showed that the optimal amount of PMA in the carbon precursor was about $5 \%$ which is clearly seen in Fig. 1.

The results of electrical conductivity measurements performed for the carbons obtained in the different conditions are summarized in Table 1. The data are consistent with the results of Raman measurements. The increase of the pyrolysis temperature as well as the increase of pyrolysis time improved electrical conductivity. Evaluation of electrical properties of obtained carbons showed that the optimal amount of PMA in MPNVF precursor was about $5 \%$ (Fig. 2), as confirmed by the results of Raman spectroscopy. Performed scanning electron microscopy (SEM) images (Fig. 3) show that there are no significant
Fig. 3 The sample SEM images of the obtained pyrolytic carbons derived from PNVF

(a) and MPNVF (b) precursors
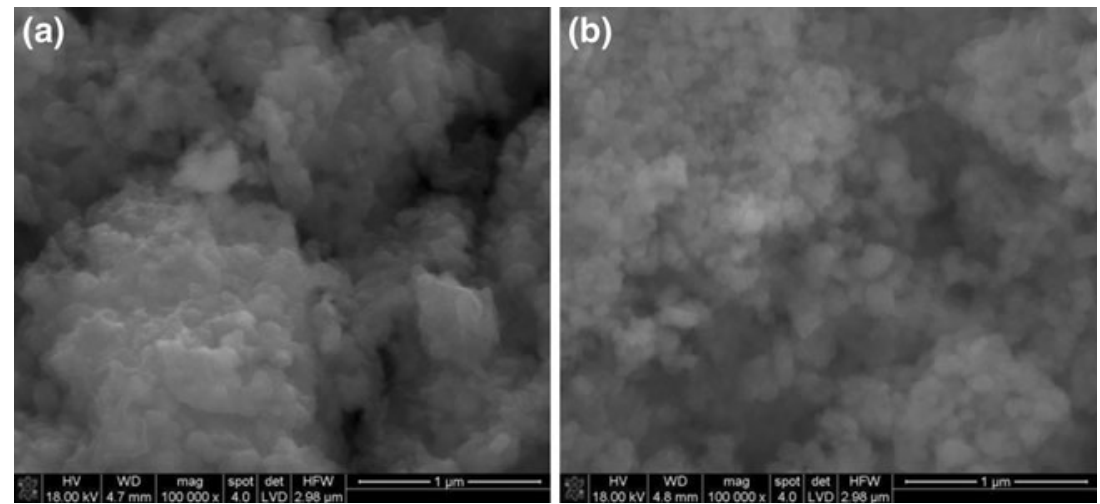


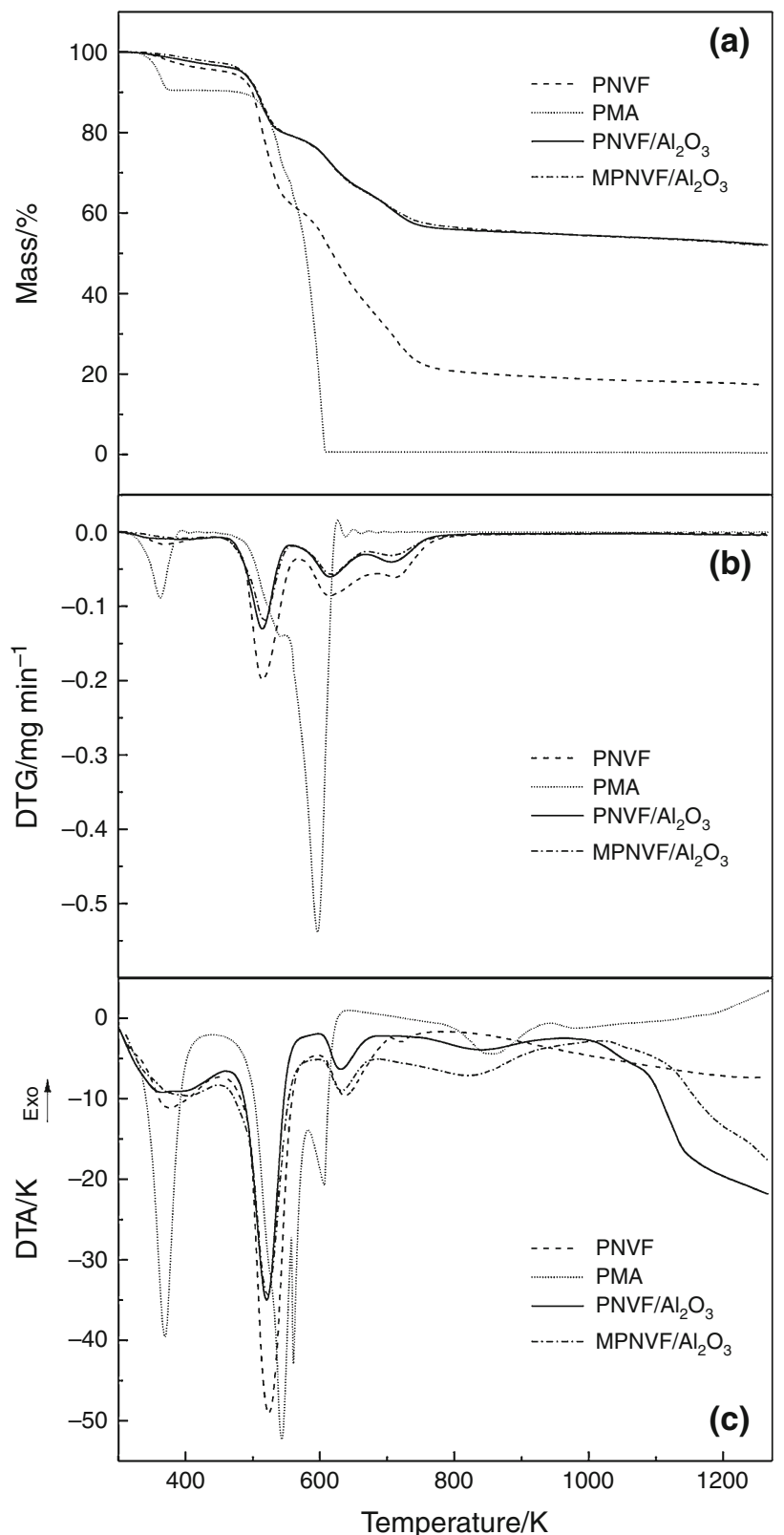

Fig. 4 Thermal analysis TG (a), DTG (b), DTA (c) of pyrolysis process of pure PMA, pure PNVF, $\mathrm{PNVF} / \alpha-\mathrm{Al}_{2} \mathrm{O}_{3}$ and $\operatorname{MPNVF}(5 \%$ $\mathrm{PMA}) / \alpha-\mathrm{Al}_{2} \mathrm{O}_{3}$

differences in the morphology of the obtained carbons, which suggests that the PMA is not a carbon precursor and serves rather as structural promoter in carbonization process resulting in significantly improved electrochemical properties.

Carbonization process and products evolved during pyrolysis were investigated by TG-FTIR. The collected TG/DTG/SDTA curves for pure PMA, pure PNVF as well as $\mathrm{PNVF} / \alpha-\mathrm{Al}_{2} \mathrm{O}_{3}$ and MPNVF (5\% PMA) $/ \alpha-\mathrm{Al}_{2} \mathrm{O}_{3}$ are shown in Fig. 4, and the corresponding FTIR maps of the evolved gases are illustrated in Fig. 5. The decomposition
Time/min

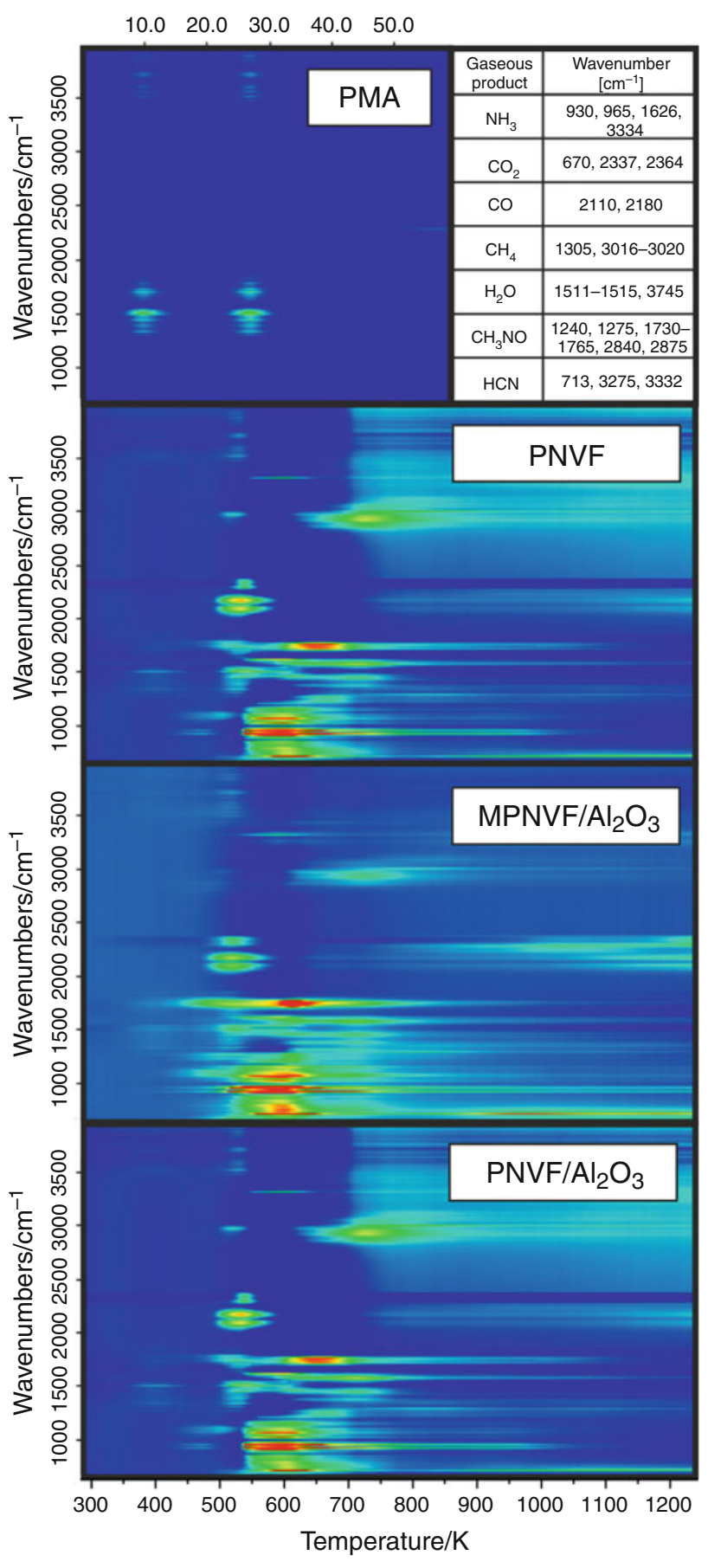

Fig. 5 FTIR maps of the gaseous products evolved during pure PMA, pure PNVF, PNVF/ $\alpha-\mathrm{Al}_{2} \mathrm{O}_{3}$ and $\operatorname{MPNVF}(5 \% \mathrm{PMA}) / \alpha-\mathrm{Al}_{2} \mathrm{O}_{3}$ decomposition

of polymeric chains begins at $406 \mathrm{~K}$ and it is connected with dehydratation process (absorption bands at 1,511-1515, $3745 \mathrm{~cm}^{-1}$, respectively, correspond to $\mathrm{H}_{2} \mathrm{O}$ [12]) and formation of $\mathrm{NH}_{3}$ (absorption bands at 930 and $965 \mathrm{~cm}^{-1}$ ). The proper carbonization process starts at $491 \mathrm{~K}$ and three stages can be distinguished. First mass 
loss $(\Delta m=\sim 15 \%)$ occurred within the temperature range of 477-533 K refers to the endothermic effect (DTA curve Fig. $4 c$ ). During this process, the side $-\mathrm{NHCHO}$ groups are decomposed with formation of CO (peaks at 2110, $2180 \mathrm{~cm}^{-1}$ ) and $\mathrm{CO}_{2}$ (peaks at 670,2337, $2364 \mathrm{~cm}^{-1}$ ) as well as from $516 \mathrm{~K} \mathrm{NH}_{3}$ (bands of 1,625 and 3,334 $\mathrm{cm}^{-1}$ ) [12-17]. The next mass loss $(\Delta m=\sim 13 \%)$, observed between 533 and $638 \mathrm{~K}$ is connected with the further emission of $\mathrm{NH}_{3}$ as well as $\mathrm{CH}_{3} \mathrm{NO}$ (1240, 1275, $\left.1730-1765,2840,2875 \mathrm{~cm}^{-1}\right)$ and $\mathrm{HCN}(713,3275$, $\left.3332 \mathrm{~cm}^{-1}\right)$. Obtained results for third stage of mass loss $(\Delta m=\sim 10 \%) 638-758 \mathrm{~K}$ corresponds with low emission of $\mathrm{CH}_{3} \mathrm{NO}$ and $\mathrm{HCN}$ and also demethanation process $\left(\mathrm{CH}_{4}\right.$ absorption bands at $\left.1305,3016-3020 \mathrm{~cm}^{-1}\right)$ $[10,12-15]$. This step of carbonization process can be related to the formation of aromatic structures. The obtained results stay consistent with our previous articles [10]. At temperatures above $758 \mathrm{~K}$ the bands ascribed to $\mathrm{HCN}$ and $\mathrm{CH}_{4}$ are still detected, but the mass loss is insignificant. For both samples MPNVF (5\% PMA)/ $\alpha$ $\mathrm{Al}_{2} \mathrm{O}_{3}$ and $\mathrm{PNVF} / \alpha-\mathrm{Al}_{2} \mathrm{O}_{3}$, the same gaseous products of carbonization were observed. It should be noticed that pure PMA does not form a carbon (Fig. 4a). However, it seems that addition of PMA to polymer precursor PNVF decreases temperature of formation of graphene condensed structures, which are the domains of electrical conductivity, which can be seen as an endothermic peak on DTA curves in Fig. 4c. This may suggest that pyromellitic acid takes the role of a promoter which structuralizes graphitization of the polymer during pyrolysis. Most probably, the planar structure of the PMA molecule accelerates nucleation process (PMA serves as a nuclei) thus facilitates the formation of graphene domains and two-dimensional crystallization of a graphite-like material. As a result of PMA addition to MPNVF polymer precursor, more graphene domains are formed during pyrolysis process at lower temperature (nucleation process is a limiting step). Moreover, this mechanism explains well about the observed effect of optimal amount of $5 \%$ PMA (Figs. 1,2). The excess of PMA nuclei must result in concurrent formation of higher amount of smaller graphene domains with lower ordering, thus the electrical properties are affected.

The carbon content in the carbonized composite samples $\left(\mathrm{CCL} / \alpha-\mathrm{Al}_{2} \mathrm{O}_{3}\right)$ was determined by TPO method [9]. The carbon deposits were oxidatively gasified in thermobalance within the temperature range of 303-1,073 $\mathrm{K}$ with heating rate of $10 \mathrm{~K} \mathrm{~min}^{-1}$ in air. The oxidation of carbonaceous deposits occurred in one step between 703 and $923 \mathrm{~K}$ accompanying with an exothermic effect proportional to carbon content.

The electrical properties of the composites $\mathrm{CCL} / \alpha$ $\mathrm{Al}_{2} \mathrm{O}_{3}$ derived from MPNVF (5\% PMA) and PNVF precursors pyrolysed at $873 \mathrm{~K}$ are also presented in Table 1 .
The amount of pyrolytic carbon in presented composites was about $20 \%$ by mass for both the samples. The composites showed very high values of electrical conductivity. Moreover, the best electrical properties are observed for composite obtained from MPNVF precursor. It should be noticed that in the composites electrical charge transport is realized only through CCL, because the host material $\left(\alpha-\mathrm{Al}_{2} \mathrm{O}_{3}\right)$ is an electrical insulator. So, one may conclude that continuous electrical wiring was successfully formed on surface of the support grains.

\section{Conclusions}

Water soluble, hydrophilic polymers may be applied as versatile precursors of pyrolytic carbons. Studies have shown that an effective precursor of pyrolytic carbons is PNVF with PMA addition. PMA in polymer precursor composition improves electrical properties of the resulting pyrolytic carbons. Raman measurements have shown that the increase of pyrolysis temperature as well as time of pyrolysis decrease $\mathrm{D} / \mathrm{G}$ band ratio confirming better graphitization and formation of graphene domains. It was found that the optimum amount of PMA in the polymer composition was about $5 \%$. Direct deposition of the PNVF as well as optimized composition of MPNVF on $\alpha-\mathrm{Al}_{2} \mathrm{O}_{3}$ fine grains by wet impregnation has been confirmed. $\mathrm{CCL} / \alpha-\mathrm{Al}_{2} \mathrm{O}_{3}$ composite derived from MPNVF precursor showing electrical conductivity better than $10^{-3} \mathrm{~S} \mathrm{~cm}^{-1}$ with activation energy of electrical conductivity as $E_{\mathrm{a}}=0.12 \mathrm{eV}$. It was shown that the addition of PMA to polymer precursor PNVF decreases temperature of formation of graphene condensed structures, domains of electrical conductivity, thus the temperature of pyrolysis process may be decreased without any impact to electrical properties of resulting pyrolytic carbons.

Acknowledgements This study has been financially supported by the Polish National Science Centre under research Grant no. N N209 088638, and by the European Institute of Innovation and Technology under the KIC InnoEnergy NewMat project. The part of the measurements was carried out with the equipment purchased thanks to the financial support of the European Regional Development Fund in the framework of the Polish Innovation Economy Operational Program (POIG.02.01.00-12-023/08).

Open Access This article is distributed under the terms of the Creative Commons Attribution License which permits any use, distribution, and reproduction in any medium, provided the original author(s) and the source are credited.

\section{References}

1. Ligneel E, Lestriez B, Hudhomme A, Guyomard D. Shaping of advanced ceramics: the case of composite electrodes for lithium batteries. J Eur Ceram Soc. 2009;29:925-9. 
2. Ligneel E, Lestriez B, Richard O, Guyomard D. Optimizing lithium battery performance from a tailor-made processing of the positive composite electrode. J Phys Chem Solids. 2006;67:1275.

3. Dubarry M, Gaubicher J, Moreau P, Guyomard D. Formation of $\mathrm{Li}_{1+\mathrm{n}} \mathrm{V}_{3} \mathrm{O}_{8} / \beta-\mathrm{Li}_{1 / 3} \mathrm{~V}_{2} \mathrm{O}_{5} / \mathrm{C}$ nanocomposites by carboreduction and resulting improvements of the capacity retention. J Phys Chem Solids. 2006;67:1312.

4. Lin $\mathrm{B}$, Wen $\mathrm{Z}$, Han $\mathrm{J}$, Wu X. Electrochemical properties of carbon-coated $\mathrm{Li}\left[\mathrm{Ni}_{1 / 3} \mathrm{Co}_{1 / 3} \mathrm{Mn}_{1 / 3}\right] \mathrm{O}_{2}$ cathode material for lithium-ion batteries. Solid State Ionics. 2008;179:1750.

5. Guo R, Shi P, Cheng X, Du C. Synthesis and characterization of carbon-coated $\mathrm{LiNi}_{1 / 3} \mathrm{Co}_{1 / 3} \mathrm{Mn}_{1 / 3} \mathrm{O}_{2}$ cathode material prepared by polyvinyl alcohol pyrolysis route. J Alloy Compd. 2009; 473:53.

6. Hassoun J, Derrien G, Panero S, Scrosati B. The role of the morphology in the response of $\mathrm{Sb}-\mathrm{C}$ nanocomposite electrodes in lithium cells. J Power Sour. 2008;183:339.

7. Kim JK, Cheruvally G, Ahn J-H, Ahn H-J. Electrochemical properties of $\mathrm{LiFePO} 4 / \mathrm{C}$ composite cathode material: carbon coating by the precursor method and direct addition. J Phys Chem Solids. 2008;69:1257.

8. Doeff MM, Wilcox JD, Kostecki R, Lau G. Optimization of carbon coatings on $\mathrm{LiFePO}_{4}$. J Power Sour. 2006;163:180-4.

9. Molenda M, Dziembaj R, Piwowarska Z, Drozdek M. A new method of coating powdered supports with conductive carbon films. J Therm Anal Calorim. 2007;88:503.
10. Molenda M, Dziembaj R, Drozdek M, Podstawka E, Proniewicz LM. Direct preparation of conductive carbon layer (CCL) on alumina as a model system for direct preparation of carbon coated particles of the composite Li-ion electrodes. Solid State Ionics. 2008;179:197-201.

11. Molenda M, Dziembaj R, Kochanowski A, Bortel E, Drozdek M, Piwowarska Z. Process for the preparation of conductive carbon layers on powdered supports. Patent Application: PCT PL2009/ 000081; WO 2010/021557; US 2011/0151112; KR 10-20117004142; JP Z-1690/GP/357/2011.

12. IR Spectrums. In: NIST Chemistry WebBook. http://webbook. nist.gov/chemistry. Accessed 1 Mar 2013.

13. Singh S, Wu Ch, Williams PT. Pyrolysis of waste materials using TGA-MS and TGA-FTIR as complementary characterisation techniques. J Anal Appl Pyrol. 2012;94:99-107.

14. Meyers RA, editor. John coates in encyclopedia of analytical chemistry. interpretation of infrared spectra, a practical approach. Chichester: Ó John Wiley \& Sons Ltd; 2000.

15. Xie W, Pan W-P. Thermal characterization of materials using evolved gas analysis. J Therm Anal Calorim. 2001;65:669-85.

16. Miller TW. Use of TG/FT-IR in material characterization. J Therm Anal Calorim. 2011;106:249-54.

17. Loría-Bastarrachea M, Herrera-Kao W, Cauich-Rodríguez J, Cervantes-Uc J, Vázquez-Torres H, Ávila-Ortega A. A TG/FTIR study on the thermal degradation of poly(vinyl pyrrolidone). J Therm Anal Calorim. 2011;104:737-42. 